\title{
S4 Statistical analysis
}

The purpose of this section is to support our findings with rigorous goodness-of-fit analysis. For result in Figure 6, we provide the parametric model that give the best fit of the data with $95 \%$ confidence interval:

$$
\begin{aligned}
\log _{10} \# \text { colocations } & =a+b \cdot \log _{10} \# \text { calls }+c \cdot \log _{10} \text { distance } \\
a & =-0.0842 \pm 0.0146 \\
b & =0.6042 \pm 0.0021 \\
c & =-0.0822 \pm 0.0034
\end{aligned}
$$

Using standard curve fitting analysis, we evaluated goodness-of-fit statistics calculating the sum of squares due to error (SSE) 2.6 $10^{4}$, the R-square 0.61, adjusted R-square 0.61 and the root mean squared error (RMSE) 0.37 . 